\title{
Study on Effect of Remaining Dentin Thickness and Coronal Pulp Size on Dentin Hypersensitivity Following Tooth Preparation
}

\author{
Ashok Ayer \\ Department of Conservative Dentistry and Endodontics, B. P. Koirala Institute of Health Sciences, Dharan- \\ 18 , Nepal
}

\section{Correspondence}

Dr. Ashok Ayer

Department of Conservative

Dentistry and Endodontics, B.

P. Koirala Institute of Health

Sciences, Dharan-18, Nepal

Email:

ashokayer@gmail.com

DOI: http://dx.doi.org/10.3126/ jemsn.v14i1.17867

Orcid ID: orcid.org/0000-0002 $-7933-8631$

Article received: July $28^{\text {th }} 2017$ Article accepted: Feb $21^{\text {st }} 2018$

\begin{abstract}
Background \& Objectives: Dentin hypersensitivity and pain following tooth preparation of vital teeth occurs with a highly variable prevalence often leading to constant pain requiring endodontic therapy. The study was conducted with objective to evaluate the impact of remaining dentin thickness, coronal pulp size, tooth wear on dentin hypersensitivity following tooth preparation. Materials \& Methods: Total 138 permanent vital teeth for abutment of fixed partial prosthesis were included in the study. Tooth wear measured using 'exact tooth wear index' and level of sensitivity to stimuli was recorded using a numerical rating scale. Following tooth preparation radiograph using paralleling technique were used for measurement of remaining dentin thickness and pulp chamber. Results: The multiple linear regression predictor model summary and overall fit statistics indicated a high degree of correlation $(\mathrm{R}=0.661,0.889,0.839$ for anterior, premolar and molar teeth respectively). The total variation for pain could be explained in $43.7 \%$ (anterior), 79.1\% (premolar), and 70.4\% (molar) by the independent variables and there was a significant linear relationship between the variables in the model $(\mathrm{p}<.001)$. Conclusion: This study investigated few possible variables that may be taken into consideration before referring the vital abutment tooth for intentional root canal therapy so that every attempt can be made to avoid pulp amputation.
\end{abstract}

Key words: Dentin hypersensitivity; Remaining dentin thickness; Tooth preparation; Tooth wear

Citation: Ayer A. Study on Effect of Remaining Dentin Thickness and Coronal Pulp Size on Dentin Hypersensitivity Following Tooth Preparation. JCMS Nepal. 2018;14(1):1-6.

\section{INTRODUCTION}

Tooth preparation may be regarded as a common dental operative procedure that might result into minor pulpal insult, but it may result in several pulpal reactions. Tooth preparation may disrupt odontoblastic processes, leading to irreversible damage of odontoblasts. ${ }^{1}$ Matthews and Vongsavan $^{2}$ stated that hydrodynamic stimulation of exposed dentin evoked the release of neuropeptides from nerve terminals that leads to increase in local blood flow, tissue pressure resulting in an outward flow of fluid in dentinal tubules. Use of cutting burs in handpiece produce frictional heat and vibration that leads to inward fluid shift and outward fluid shift due to evaporative water loss and slight inward fluid shift due to osmotic movement of cooling water into dentin.

The degree of dentinal sensitivity is strongly related to the exposed dentinal tubules. ${ }^{3}$ A- Fibers respond to a number of different hydrodynamic stimuli including dentinal probing, air blasts and hyperosmotic solutions, they induce fluid flow in the dentinal tubules. ${ }^{4}$ Responses of the connective tissue of the pulp to several types of injuries are highly dependent on the degree of dentinal damage and resultant status of dentin permeability. ${ }^{1}$ Post 
cementation sensitivity following crown placement is as high as $23 \%$ and loss of pulp vitality approximately $1 \%$ per year. ${ }^{5}$ Pulpal injury can occur at any stages of tooth preparation and crown cementation. During tooth preparation, a large number of highly permeable dentinal tubules are exposed. Dentin is an excellent insulator because it is a poor thermal conductor, ${ }^{6}$ but the high surface temperature may expand the dentinal fluid immediately beneath poorly irrigated burs. If the rate of expansion of dentinal fluid is high, may create shear forces sufficiently larger to tear the cell membrane and induce calcium entry into the cell, possibly leading to cell death. ${ }^{6}$

Despite the inherent limitation of being the twodimensional image of a three- dimensional object, clinician relies on Intra oral Periapical radiograph (IOPAR) or bitewing radiographs as a routine diagnostic tool for diagnosis and treatment plan for tooth preparation and restorative procedures. Results of this study may provide an opportunity to the dentist of preoperative evaluation before treatment planning and possible treatment outcome.

\section{MATERIALS AND METHODS}

This study was conducted with the approval of the ethical committees of National Health Research Council, Nepal (Reg. no. 65/2015) and B. P. Koirala Institute of Health Sciences, Dharan, Nepal. Study Population: Total 138 patient of age range 18 -60 years attending dental OPD for the crown and/ or fixed partial denture with at least one vital abutment. Inclusion Criteria: Vital permanent teeth, teeth with or without regressive alteration. Exclusion Criteria: Tooth with carious lesion, moderate to severe periodontal disease, periapical pathosis, traumatic injury to tooth, mal-alignment of tooth, atypical tooth morphology, developmental disorders affecting teeth and/or oral structures, difficult to obtain radiographic image, medical (including psychiatric) and pharmacotherapeutic histories that may compromise the protocol including the chronic use of anti-inflammatory, analgesic and mind-altering drugs, systemic conditions that are etiologic or predisposing to dentine hypersensitivity (e.g., chronic acid regurgitation), excessive dietary or environmental exposure to acids, periodontal surgery in the preceding three months, orthodontic appliance treatment within previous three months, teeth or supporting structures with any other painful pathology or defects, teeth restored in the preceding three months, extensively restored teeth and those with restorations extending into the test area.

Sampling Methods/Techniques: Random sampling. Everyone that satisfy inclusion criteria was provided with a coded random number, operator \& patient were kept blind before the procedure, following the completion of tooth preparation the code was matched to find out whether the patient falls under the study sample or not. Clinical Assessment: Following informed consent, patient assessment was done before and after the tooth preparation. Tactile stimulation was done by passing an explorer cervically over the abutment tooth. To produce evaporative stimuli: 2 seconds air blast was delivered using the dental unit triple syringe, blowing a short blast of room temperature air, being held perpendicular and $2 \mathrm{~mm}$ away from tooth surface, whilst shielding the adjacent teeth with cotton rolls. ${ }^{7}$ Immediately following stimulation, the subjects were asked to grade their overall sensitivity using a numerical rating scale (NRS) labelled at the extremes of "no pain," at the zero end of the scale, and "severe pain," at another end of the scale. Radiographic assessment: Intraoral periapical radiograph (IOPAR) using paralleling technique by the aid of positioning device (Rinn XCP, Dentsply, USA) were produced after completion of the tooth preparation. Digital images of the radiographs were made keeping the standard scale at the side of the image. Image $J$ software (National Institutes of Health, Bethesda, Maryland, USA) was used for measurement of the radiographic images.

Dentin thickness: $A=$ from mesial pulp horn to the occlusal surface; $B=$ from distal pulp horn to the occlusal surface; $C=$ from the proximal surface at the level of pulp horn; $\mathrm{D}=$ from the proximal surface at CEJ (Cemento enamel Junction) level. The shortest dimension up to the external surface was considered as remaining dentin thickness (RDT). Pulp size measurement: Pulp area in the clinical crown $\left(\mathrm{mm}^{2}\right)$ : Up to the level of CEJ. The buccal, cervical, incisal/occlusal, palatal/ lingual surface of the selected teeth was scored according to the 'The Exact tooth wear index'. ' Scores of $0-4$ for the enamel and 0-5 for the dentine were assigned to the teeth, according to the severity of wear. ${ }^{8}$

Statistical Methods: Collected data was entered in Microsoft Excel and coded accordingly. The statistical analysis was performed by statistical package for social science (SPSS). For Inferential statistics, Spearman's rank correlation coefficient was applied to measure the strength of association 


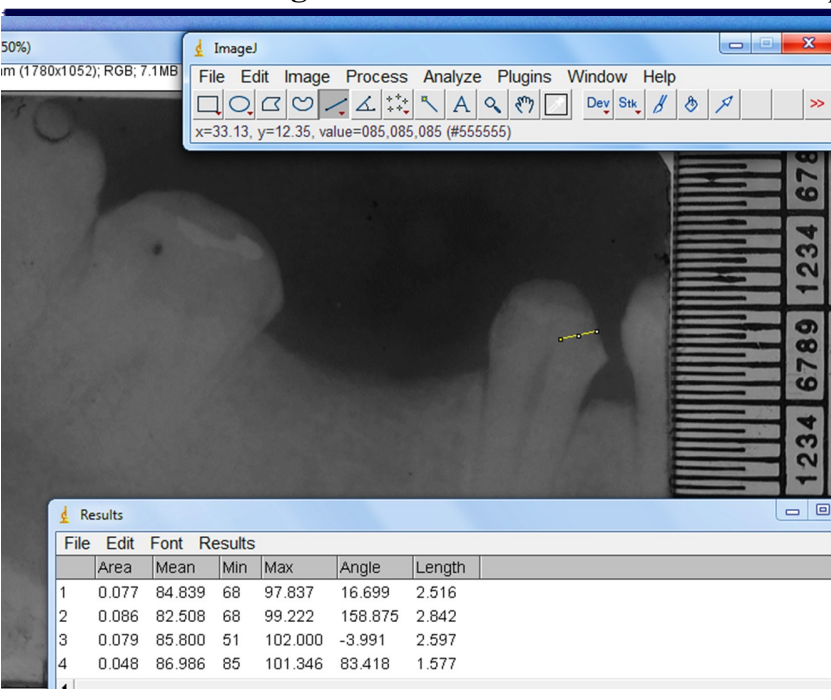

Figure: 1- Radiographic measurement using Image $\mathbf{J}$ Software.

between variables. Categorical variables among the independent variables were transformed into dichotomous dummy variables and recoded into different variables. Shapiro-Wilk test shows normal distribution of the dependent variable. Following Correlation test, predictors showing significant association with the dependent variable were selected for regression analysis. Standard multiple linear regression followed by stepwise regression analysis was performed to obtain a best-fit equation.

\section{RESULTS}

Total 64 male and 74 females were enrolled in the observation. The dependent variable was pain following tooth preparation (i.e. dentinal hypersensitivity) and independent variables (predictors) were remaining dentin thickness (RDT), pulp chamber area, baseline pain (baseline dentinal hypersensitivity), tooth wear index (Exact tooth wear Index), tooth morphology (anterior, premolar, molar), gender, age. Following statistical observation pulp chamber area, gender and age were not significantly correlated with the dependent variable and hence did not contribute to the multiple regression models.

Table 1: $\mathrm{R}$ is the correlation coefficient. The total variation for pain following tooth preparation can be explained by "R square" of the variance in the data (Independent variables). The "Std. Error of the Estimate" shows that the standard deviation of the residuals shows acceptable fit and no estimation error.

The Durbin-Watson, which is between the two critical values of $1.5<\mathrm{d}<2.5$ signifies that there is no first order linear auto-correlation in the multiple linear regression data.

The F-test is highly significant, thus there is a linear relationship between the variables in this model. $p$ $<0.01$, the model is a good fit for the data.

Table 1: Regression analysis Model Summary

\begin{tabular}{|c|c|c|c|c|c|c|}
\hline $\mathbf{R}$ & $\begin{array}{c}\mathbf{R} \\
\text { Square }\end{array}$ & $\begin{array}{l}\text { Std. Error of the } \\
\text { Estimate }\end{array}$ & Durbin-Watson & F- Test & p-value & Residual Stat. \\
\hline \multicolumn{7}{|c|}{ Pain following tooth preparation } \\
\hline 0.791 & 0.625 & 1.235 & 1.512 & 13.581 & $<.001$ & $<3$ to $>-3$ \\
\hline \multicolumn{7}{|c|}{ Pain following tooth preparation in "anterior teeth" } \\
\hline 0.661 & 0.437 & 1.565 & 1.720 & 3.099 & $<.01$ & $<3$ to $>-3$ \\
\hline \multicolumn{7}{|c|}{ Pain following tooth preparation in "premolar teeth" } \\
\hline 0.889 & 0.791 & .883 & 1.906 & 10.385 & $<.001$ & $<3$ to $>-3$ \\
\hline \multicolumn{7}{|c|}{ Pain following tooth preparation in "molar teeth" } \\
\hline 0.839 & 0.704 & 1.210 & 1.526 & 6.552 & $<.001$ & $<3$ to $>-3$ \\
\hline \multicolumn{7}{|c|}{ Pain after 1 week of tooth preparation } \\
\hline 0.855 & 0.731 & 1.020 & 1.844 & 16.895 & $<.001$ & $<3$ to $>-3$ \\
\hline \multicolumn{7}{|c|}{ Pain after 1 week of tooth preparation in "anterior teeth" } \\
\hline 0.867 & 0.752 & 1.008 & 2.008 & 12.112 & $<.001$ & $<3$ to $>-3$ \\
\hline \multicolumn{7}{|c|}{ Pain after 1 week of tooth preparation in "premolar teeth" } \\
\hline 0.875 & 0.758 & 1.005 & 1.680 & 6.267 & $<.001$ & $<3$ to $>-3$ \\
\hline \multicolumn{7}{|c|}{ Pain after 1 week of tooth preparation in "molar teeth" } \\
\hline 0.840 & 0.706 & 1.093 & 2.074 & 6.593 & $<.001$ & $<3$ to $>-3$ \\
\hline
\end{tabular}


Normal P.P Plot of Regression Standardized Residual

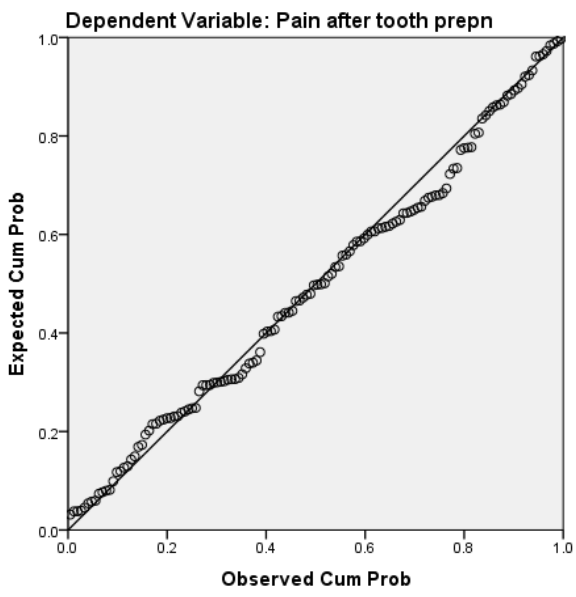

Figure 2: The homoscedasticity and normality of residuals with the Q-Q-Plot of $\mathrm{z}^{*}$ pred and $\mathrm{z}^{*}$ resid. The plot indicates that in the multiple linear regression analysis there is no tendency in the error terms.
This prospective clinical study was conducted to provide the multivariable model to explain factors affecting dentinal hypersensitivity following tooth preparation and to find the effect of the amount of tooth structure that is remaining following tooth preparation, which may be used as a model to explain level or severity of tooth sensitivity which occasionally may end-up in root canal treatment. So the study attempts to evaluate multiple factors that could be assessed before tooth preparation for placement of crown or fixed partial denture so as to identify the problems and address it in the treatment planning. Table 2 shows that the most influential factor in predicting the incidence of pain following tooth preparation is the remaining dentin thickness.

All restorative procedures cause pulpal irritation to a different extent. The pulp has inherent defence

Table 2: The equation for the multiple linear regression models

Pain following tooth preparation $=9.378+(-2.912)$ RDT $+(0.482)$ Baseline pain $+(-0.737)$ Premolar teeth $+(-1.274)$ Enamel Buccal-1

Pain following tooth preparation in 'anterior teeth' $=9.357+(-2.815) \mathrm{RDT}$

Pain following tooth preparation in 'premolar teeth' $=8.399+(-2.728) \mathrm{RDT}+(0.471)$ Baseline pain $+(-$ 1.453) Enamel Buccal-1

Pain following tooth preparation in 'molar teeth' $=10.624+(-3.529) \mathrm{RDT}+(0.998)$ Baseline pain $+(-$ 1.665) Enamel Cervical-3

Pain after 1 week of tooth preparation $=1.424+(0.580)$ Pain following tooth prepn.$+(-0.777)$ RDT + (0.235) Baseline pain

Pain after 1 week of tooth preparation in anterior teeth $=3.099+(0.518)$ Pain following tooth prepn. $+(-$ 1.564) RDT + (1.133) Enamel Cervical-3

Pain after 1 week of tooth preparation in 'premolar teeth' $=-0.654+(0.802)$ Pain following tooth preparation. + (1.745) Enamel Occlusal-4

Pain after 1 week of tooth preparation in 'molar teeth' $=-0.516+(0.715)$ Pain following tooth preparation.

RDT (Remaining Dentin Thickness), Enamel Buccal-1 (Loss of enamel affecting less than $10 \%$ of the Buccal surface), Enamel cervical-3 (Enamel loss affecting at least one third but less than two thirds of the cervical surface), Enamel occlusal-4 (Enamel loss affecting two thirds or more of the occlusal surface).

Std Residual and Stud Residual values lies between; $<3$ to $>-3$. Shows that, there is no discrepancy of values on the regression estimates.

These equations can be used to predict the role of independent variables that will influence dependent or outcome variable

\section{DISCUSSION}

mechanisms to limit the damage caused by irritants. Several restorative procedures attempt to provide a barrier to external irritants. The natural protective barrier is remaining dentin thickness, no material can be placed in a tooth provides better protection for the pulp than dentin. Dentin along with the dentinal fluid has excellent buffering capability to neutralize the acidic environment, ${ }^{9,10}$ and it also 
provides insulation to the pulp from the increasing temperature during tooth preparation. ${ }^{11}$ In vitro studies reported that $0.5 \mathrm{~mm}$ of the remaining dentin thickness reduces the toxic effect of the pulp by $75 \%$ and $1 \mathrm{~mm}$ of the remaining dentin thickness reduces it by $90 \% .^{12}$ Least effect of the toxic substance on the pulp occurs when the remaining dentin thickness is $2 \mathrm{~mm}$ or more.

The equation for the multiple regression model for pain after one week of tooth preparation shows that apart from RDT and tooth wear, the pain following tooth preparation is another significant influential variable, which was observed to be even more affecting in the premolar teeth, which may be possible due to the relatively less RDT after abutment preparation in the premolar teeth. When the remaining dentin thickness is less than $0.25 \mathrm{~mm}$ to $0.3 \mathrm{~mm}$, more severe pulpal response occurs, ${ }^{13,14}$ which may result in an inflammatory response in the pulp. Even though in the absence of bacterial infection the transient toxic effect of the dental material is reduced but the less remaining dentin thickness poses constant challenge towards susceptibility to infection due to increased susceptibility of bacterial contamination. Thus the remaining dentin thickness plays a critical role in providing a barrier to the dental pulp.

During tooth preparation for the crown the instrument cuts both enamel and dentin from the significantly larger surface area of the tooth. Langeland et al..$^{15}$ reported that the temperature rise during preparation of enamel and dentin combined is considerably greater than of preparing dentin alone. During the study period, eight patients experienced constant pain and sensitivity that did not reduce after one week, the patients were kept under oral analgesic and provisional restoration. After two weeks the abutment was managed with intentional root canal therapy to alleviate pain and discomfort. Lockard $\mathrm{MW}^{16}$ performed a study of pulpal response in vital teeth prepared for full veneer crown restoration using only air coolant, suggested that the factors responsible for minimizing the need for post restoration endodontic therapy are; high-speed handpiece, light force (1- 3 $\mathrm{Oz}$ ), new-burs, air coolant and intermittent water spray from the air- water syringe. However, the severity of the pulpal reaction is dependent upon the amount of frictional heat and desiccation of dentin. $^{15,17}$ During tooth preparation the heat generated by friction may cause burn lesion in the pulp and abscess formation. ${ }^{18}$ Due to desiccation of dentin during tooth preparation, the dentin becomes more permeable and the lost fluid may be filled with chemicals that may elicit harmful response to pulp. $^{15}$

\section{CONCLUSION}

Clinical decision making about referring the vital tooth for intentional root canal therapy so as to avoid possible dentinal hypersensitivity or possibility of pulp exposure is mostly based upon the judgment of the clinician. This study investigated few possible variables that may be taken into consideration while planning for crown or fixed partial denture in which abutment is vital teeth. The study shows that there is a significant influence of the observed variables towards the contribution of pain following tooth preparation i.e. dentine hypersensitivity.

\section{Funding}

External funding was not received for this study.

\section{Conflict of Interest Statement:}

\section{None Declared}

\section{REFERENCES}

1. Okiji T. Pulp as a Connective Tissue. In: Kenneth HM, Goodis EH, editors. Seltzer and Bender's Dental Pulp. Quintessence Publishing Co.; 2002. p. 95-117. https:// doi.org/10.1038/sj.bdj.2012.717.

2. Matthews B, Vongsavan N. Interaction between neural and hydrodynamic mechanisms in dentin and pulp. Arch Oral Biol. 1994;39:878-978. https://doi.org/10.1016/0003-9969 (94)90193-7. PMID: 7702472.

3. Närhi M, Yamamoto H, Ngassapa D, Hirvonen T. The neurophysiological basis and the role of inflammatory reactions in dentine hypersensitivity. Arch Oral Biol. 1994;39:S23-S30. http://dx.doi.org/10.1016/0003-9969(94) 90184-8. PMID: 7702462 .

4. Margaret R, Byers, Matti V. Nerve supply of the Pulpodentin complex and response to injury. In: Hargreaves KM, Goodis HE, editors. Seltzer and Bender's Dental Pulp. Quintessence Publishing Co; 2002. p. 151174. https://doi.org/10.1038/sj.bdj.2012.717.

5. Johnson GH, Powell LV, DeRouen TA. Evaluation and Control of Post-Cementation Pulpal Sensitivity: Zinc Phosphate and Glass Ionomer Luting Cements. J Am Dent Assoc. $1993 \quad$ Nov;124(11):38-46. http:// dx.doi.org/10.14219/jada.archive.1993.0221. PMID: 8227772 .

6. Goodis HE, Pashley D, Stabholtz A. Pulpal effects of thermal and mechanical irritants. In: Hargreaves KM, Goodis HE, editors. Seltzer and Bender's Dental Pulp. Quintessence Publishing Co; 2002. p. 371-384. https:// doi.org/10.1038/sj.bdj.2012.717

7. Fares J, Shirodaria S, Chiu K, Ahmad N, Sherriff M, Bartlett D. A new index of tooth wear. Caries Res. 2009;43 (2):119-25. DOI: 10.1159/000209344.

8. Ayer A. Association between Severity of Tooth Wear and Dentinal Hypersensitivity. JCMS Nepal. 2016;12(3):94-8. http://dx.doi.org/10.3126/jcmsn.v12i3.15487.

9. Spangberg LS, Hellden L, Robertson PB, Levy BM. Pulpal effects of electrosurgery involving based and unbased cervical amalgam restorations. Oral Surg Oral Med Oral 
Pathol. 1982;54(6):678-85. http://dx.doi.org/10.1016/00304220(82)90083-4. PMID: 6961345.

10. Brannstrom M. Communication between the oral cavity and the dental pulp associated with restorative treatment. Oper Dent. 1984;9(2):57-68. PMID:6591138.

11. Öztürk B, Üşümez A, Öztürk AN, Ozer F. In vitro assessment of temperature change in the pulp chamber during cavity preparation. J Prosthet Dent. 2004 May;91 (5):436-40. http://dx.doi.org/10.1016/ j.prosdent.2004.02.022. PMID: 15153850.

12. MERYON SD. The model cavity method incorporating dentine. Int Endod J. Wiley-Blackwell; 2007 Sep 25;21 (2):79-84. http://dx.doi.org/10.1111/j.13652591.1988.tb00959.x. PMID: 3268557.

13. Murray PE, About I, Lumley PJ, Franquin JC, Remusat M, Smith AJ. Cavity remaining dentin thickness and pulpal activity. Am J Dent. 2002 Feb;15(1):41-6. PMID: 12074229.

14. De Souza Costa CA, do Nascimento ABL, Teixeira HM Response of human pulps following acid conditioning and application of a bonding agent in deep cavities. Dent Mater. 2002 Nov;18(7):543-51. http://dx.doi.org/10.1016/s01095641(01)00089-6. PMID: 12191668.

15. Langeland K, Langeland L. Cutting procedures with minimized trauma. J Am Dent Assoc. 1968 May ;76(5):991 -1005. http://dx.doi.org/10.14219/jada.archive.1968.0181. PMID: 4868947.

16. Lockard MW. A retrospective study of pulpal response in vital adult teeth prepared for complete coverage restorations at ultrahigh speed using only air coolant. J Prosthet Dent. 2002 Nov;88(5):473-8. http:// dx.doi.org/10.1067/mpr.2002.129380. PMID: 12473995 .

17. Hamilton AI, Kramer IR. Cavity preparation with and without water spray. Effects on the human dental pulp and additional effects on further dehydration of the dentin. British Dent J. 1967 Sept;123(6):281-5. PMID:4864148.

18. Stanley HR, Swerdlow H. Reaction of the human pulp to cavity preparation: results produced by eight different operative grinding techniques. J Am Dent Assoc. 1959 May ;58(6):49-59. http://dx.doi.org/10.14219/ jada.archive. 1959.0125 